\title{
CLINICAL STUDY OF TYPE III COMPOUND TIBIAL FRACTURES IN ADULTS BY PRIMARY EXTERNAL FIXATION METHOD
}

\author{
Sumanth Babu Yalamanchili1, Suresh Babu Surapaneni²
}

${ }^{1}$ Assistant Professor, Department of Orthopaedics, Dr. Pinnamaneni Siddhartha Institute of Medical Sciences and Research Foundation, Chinoutpalli, Andhra Pradesh.

${ }^{2}$ Professor, Department of Orthopaedics, Dr. Pinnamaneni Siddhartha Institute of Medical Sciences and Research Foundation, Chinoutpalli, Andhra Pradesh.

\begin{abstract}
BACKGROUND

With increasing vehicular traffic, industrialisation, urbanisation, the incidence of open fractures of tibia has increased in our present day practice. High velocity trauma producing severe bone and soft tissue injuries have become very common cause of morbidity and mortality. The tibia and fibula are the most frequent open fractured long bones due to high velocity trauma. Despite the advent of new generation of antibiotics, meticulous debridement and recent technological advances in fracture fixation methods, the management of an open fracture of tibia remains problematic.
\end{abstract}

\section{MATERIALS AND METHODS}

This study consisted of 30 cases of Type III compound tibial fractures treated by wound debridement and by primary stabilisation with external fixator. 28 patients were injured due to RTA and 7 patients found to be having associated fractures.

\section{RESULTS}

Mean age was 38.87 years, $80 \%$ of the fractures were middle and lower third both-bone fracture. There were 25 secondary procedures done in 30 cases, Split skin grafting in 13, Transposition flap in 5, Bone grafting in 2, Intramedullary nail in 3, Ilizarov in 2 patients. Healing time with full weight bearing was 6.2 months and $74 \%$ got good to excellent result.

\section{CONCLUSION}

By knowing the technique and biomechanics, application of external fixator can act as a definite and safest method of treatment in open tibial fractures.

\section{KEYWORDS}

Open Tibia Fracture, External Fixator, Secondary Procedures.

HOW TO CITE THIS ARTICLE: Yalamanchili SB, Surapaneni SB. Clinical study of type iii compound tibial fractures in adults by primary external fixation method. J. Evolution Med. Dent. Sci. 2017;6(2):106-109, DOI: 10.14260/Jemds/2017/27

\section{BACKGROUND}

With increasing vehicular traffic, industrialisation, urbanisation, the incidence of open fractures of tibia has increased in our present day practice. High velocity trauma producing severe bone and soft tissue injuries have become very common cause of morbidity and mortality.

The tibia and fibula are the most frequently fractured long bones due to high velocity trauma. One third of the circumference of tibia is subcutaneous and directly anterior, hence more prone to open trauma. Tibia has got a poor blood supply with the tibial nutrient artery being damaged almost always in open fractures of tibia and hence the bone is dependent on soft tissue coverage for the blood supply. Hence, further surgical exposure may make the bone avascular. Despite the advent of new generation of antibiotics, meticulous debridement and recent technological

Financial or Other, Competing Interest: None.

Submission 15-12-2016, Peer Review 27-12-2016,

Acceptance 29-12-2016, Published 05-01-2017.

Corresponding Author:

Dr. Suresh Babu Surapaneni,

Suresh Ortho \& Multi Speciality Clinic,

56-2-18, Koneru Satyanarayana Street,

Canara Bank Road, Patamata,

Vijayawada-520010, Krishna District,

Andhra Pradesh, India.

E-mail: drssureshbabu@yahoo.com

DOI: $10.14260 /$ jemds $/ 2017 / 27$ advances in fracture fixation methods, the management of an open fracture of tibia remains problematic. This may be owing to the fact that open fractures of tibia are resultant of high velocity trauma and are often displaced and comminuted with extensive loss of soft tissue cover.

Different authors propose various methods of management of compound tibial fractures which range from external fixation, 1 internal fixation with plates and screws, ${ }^{2}$ intramedullary nails with reamed or non-reamed, nonlocking or interlocking nails. ${ }^{3}$ But the definitive mechanism of immobilisation of these fractures remains a controversy.

External fixation provides excellent stability without the need for circumferential plaster dressings. ${ }^{4}$ External fixator has gained popularity. The management of type III compound fractures of leg is undertaken to study the advantages and disadvantages of primary stabilisation using external fixator, to evaluate the use, to assess the convenience of management of open wound not compromising the stability that is necessary for fracture healing.

\section{MATERIALS AND METHODS}

30 cases of compound tibial fractures treated by primary stabilisation with external fixator in our hospital were studied. This was a prospective clinical study, out of the 30 cases 28 were due to road traffic accidents, one was a case of gunshot injury and one was due to a fall of a heavy object. Majority of them, 27 were male patients and only 3 patients were female. Associated injuries and fractures were noted in 
7 patients. Both right and left sides were equally affected. One patient died of septicaemia causing cardiogenic shock with pulmonary embolism. One more patient with uncontrolled diabetes died at home after discharge due to diabetic ketoacidosis, one patient developed gas gangrene 6 days after surgery and was shifted to Endemic Diseases Hospital and lost to followup.

Life threatening problems were given priority in managing patients at casualty. When the patient was stable the management of open tibial fracture was considered. ${ }^{5}$ Assessment of extremity for viability, vascular integrity, soft tissue status, bone construct and neurological integrity was done. Essential information regarding the patient, nature of injury, extent of wound, etc was noted.

After recording of vital parameters and rapid systemic evaluation, the wounds were cleaned up with saline, dilute hydrogen peroxide, povidone-iodine and wound covered with sterile dressings. The limb was immobilised in an above knee pop slab. Depending on general condition of the patient, intravenous fluids, plasma expanders and blood transfusion were administered. ${ }^{6} \mathrm{X}$-rays and other routine investigations were carried out; associated fractures if present were recorded.

Detailed radiological study was carried out and systemic clinical examination was made. Injection Tetanus Toxoid 6 was given in the dose of $1 / 2 \mathrm{cc}$ intramuscularly to all patients and anti-tetanus serum was given to the patients with highly contaminated wounds. Intravenous antibiotics ${ }^{7}$ were started immediately for all type III fractures.

Once the patient was fit for surgery, patient was taken to major OT at the earliest. After the patient was induced either by general or spinal anaesthesia, swabs were taken and sent for culture and sensitivity. Wound was cleaned with normal saline and hydrogen peroxide.

\section{Operative Technique}

External fixation of the open diaphyseal fractures using a half pin anteromedial frame was selected as the frame of choice. 8,9 After painting and draping the limb, fracture site was exposed and reduced through the same wound and regular "wound debridement" was done. If the fracture site was not accessible in some cases, the original wound was extended slightly in order to obtain sufficient access for accurate open reduction.

Placement of first pin is either proximal most or distal most. The fracture was aligned before pins were inserted. Minimum of two pins away from each other were inserted in each fragment through maximum thickness of cortical bone. The pins inserted were as close as possible to a vertical line drawn through medial malleolus and subcutaneous surface of tibia to minimise interference with muscle action. The number of pins inserted depended on the size of the fragment, degree of comminution and were assessed according to the needs of rigidity of fracture fixation. Incisions of $0.5 \mathrm{~cm}$ long were made to prevent pin tract infection where the pins exit the skin. In most of the cases, an early attempt was made to close wounds primarily after aggressive debridement. For early flap cover plastic surgeons were also involved. Safe corridors for Schanz pin insertion in tibia are in proximal to tibial tubercle, Schanz pins can be safely inserted at an arc of $220^{\circ}$, just below the tibial tubercle safe arc decreases to $140^{\circ}$ at the distal third of leg safe arc remains $140^{\circ}$ but anterior tibial vessels and deep peroneal nerve become vulnerable as they cross the lateral tibial cortex, above the ankle joint safe arc is $120 .^{\circ}$ Pins may be inserted into the tarsal and metatarsal bones to splint the ankle Joint.

In the primary stage, stability of the fracture was given priority. Any angular or rotational deformities in the tibial fractures were corrected during the early post-operative period. The wounds on the leg and pin wounds were dressed regularly with Betadine solution to prevent pin tract infection.

Antibiotics were administered to all patients and changes were made accordingly as per culture sensitivity reports. Early active movements of the joint were encouraged. Ambulation of the patient with crutches was started as soon as the swelling of soft tissue subsided. X-rays were taken every 4 to 6 weeks. Once callus formation was evident the connecting rods were removed and the limb was tested for stability clinically. When sufficient stability was present the pins were removed and the limb was placed in a below knee functional cast brace.

The patients were called for subsequent followup to review the progress every 15 to 20 days. X-rays of the affected leg, AP and lateral views were taken at each followup and clinically examined for status of the wound, clinical and radiological evidence of fracture healing, range of mobility at knee and ankle joint, function of the limb, complications like infection of the wound, angulation, pin tract infection, shortening, etc. Fracture union was judged complete when the patient required no further cast or brace protection, had no pain on stress testing and trabecular bone crossing the fracture site was seen on X-rays.

\section{RESULTS}

The minimum age was of 14 years to maximum age of 80 years (Table-1), mean age was 38.87 years. Out of 30 cases, 27 were male (90\%). Right and left were equally distributed. Six (20\%) were upper third, 17 (56, 6\%) were middle third, 7 $(23.3 \%)$ were lower third fractures of tibia noted. Majority of the cases (28) were due to RTA, one was due to gun shot, and other was due to frame yard injury. Six associated injuries like fracture scapula, Colles' fracture, foot injury, other tibia, clavicle and medial malleoli fracture were noted. All of the patients underwent debridement, and external fixator application. There were 25 secondary procedures done in 30 cases, Split skin grafting in 13, Transposition flap in 5, Bone grafting in 2, Intramedullary nail in 3, Ilizarov in 2 patients.

Complications like pin tract infection and loosening, nonunion and ankle stiffness were noted (Table-2).

Excluding 2 deaths and one patient whom we lost followup, the healing time was assumed to be the time between injury and the beginning of full weight bearing with no external support was 6.2 months the range being 6 to 16 months. All of the patients were followed at our outpatient department. The final results after followup ranging from seven to twenty four months were evaluated according to the described Karlstrom ${ }^{10}$ criteria. The overall result of Excellent, Good, Acceptable, or Poor was then determined according to the criteria (Table-3). 


\begin{tabular}{|c|c|}
\hline Age in Years & Number \\
\hline $14-20$ & 4 \\
\hline $21-30$ & 7 \\
\hline $31-40$ & 6 \\
\hline $41-50$ & 6 \\
\hline $51-60$ & 3 \\
\hline $61-70$ & 2 \\
\hline $71-80$ & 2 \\
\hline \multicolumn{2}{|c|}{ Table 1 } \\
\hline
\end{tabular}

\begin{tabular}{|c|c|c|}
\hline No. & Complication & Cases \\
\hline 1 & Pin tract infection & 3 \\
\hline 2 & Amputation & 1 \\
\hline 3 & Pin loosening & 6 \\
\hline 4 & Chronic Osteomyelitis & 5 \\
\hline 5 & Ankle stiffness & 3 \\
\hline 6 & Delayed union & 2 \\
\hline 7 & Non-Union & 5 \\
\hline 8 & Malunion & 1 \\
\hline 8 & Neurovascular damage & 0 \\
\hline \multicolumn{2}{|c|}{ Table 2 } \\
\hline
\end{tabular}

\begin{tabular}{|c|c|c|c|}
\hline Grade & Criteria & $\begin{array}{c}\text { No. of } \\
\text { Patients }\end{array}$ & \% \\
\hline Excellent & $\begin{array}{c}\text { Fracture united. soft tissue } \\
\text { healed, no complications. } \\
\text { restoration of full function }\end{array}$ & 15 & 50 \\
\hline Good & $\begin{array}{c}\text { Fracture united. soft tissue } \\
\text { healed, minimal joint } \\
\text { stiffness, minimal } \\
\text { angulation }\end{array}$ & 7 & 23.33 \\
\hline Acceptable & $\begin{array}{c}\text { Delayed union, impairment } \\
\text { of function }\end{array}$ & 3 & 10 \\
\hline Poor & $\begin{array}{c}\text { Infected nonunion. } \\
\text { Excessive loss of function }\end{array}$ & 2 & 6.67 \\
\hline \multicolumn{3}{|c|}{ Table 3 } \\
\hline
\end{tabular}

\section{DISCUSSION}

In the present study, out of the 30 cases taken up, 27 cases were followed up regularly. One case died due to septicaemia and other one died of Diabetic ketoacidosis. One case was lost to followup. All the cases were treated as under the protocol with primary debridement and external fixation. Early wound coverage was done either by primary closure, Split Skin Graft or a transposition flap wherever necessary. Bone Grafting and Bone marrow infiltration was done for a few cases suspected of delayed union or non-union.

The compound fracture of the leg was observed to be more common between 20 to 50 years with the mean age being 39.87 years. The minimum age was 14 years and maximum age was 80 years. The age distribution could be compared to earlier studies done by Edwards et al 11 and Thakur and Patnakar's ${ }^{12}$ (mean age-38 years). Majority of our patients were male (90\%), predominance attributable to their activity and exposure to vehicular and other accidents. Similar observation was made by Edwards et al,11 Vander Linden, ${ }^{13}$ Velazco. ${ }^{14}$

In a study by Thakur and Patnakar ${ }^{12}$ (1991), males were $83.5 \%$ and females were $10 \%$. The commonest mode of injury was severe violent trauma due to Road traffic accidents (93\%). As majority of the patients were between 20 to 50 years, the incidence of associated medical problems was less. Only three patients had diabetes and three had hypertension.
In our study, incidence of right and left-sided fractures was equal. In all cases, fibula along with tibia was also fractured. There was one case of bilateral compound fracture of tibia. Culture sensitivity studies showed bacteria with varied susceptibility to second/third generation cephalosporins, aminoglycosides or quinolones. In most of the fractures, external fixation was applied within 24 hours after hospitalisation. Thorough irrigation of the wound and debridement was done. Majority of the fixators were Anterior Unilateral Uniplanar type of frame (AO type). More complex frames (Triangular) were used in two fractures which were unstable and comminuted. In one case foot was also stabilised with inclusion of the foot in to the frame. Healthy wounds which could be closed were sutured primarily (4 cases). Large areas which were healthy but could not be sutured were covered by split skin grafts (13 cases) or by flap cover ( 5 cases) either by fasciocutaneous or microvascular free flaps. Daily dressings of the open wounds were done. If necessary, the patients were considered again for serial debridement before giving wound coverage.

Once the wound cover was matured and fracture showed callus formation the external fixator was removed and PTB cast applied. If there was no signs of fracture healing in 12 weeks and in cases with Bone loss early bone grafting was done. In this study, commonly encountered complications were pin tract infection 3 cases (10\%), ankle stiffness in 3 cases $(10 \%)$, Non-union in 5 cases $(16.67 \%)$. Staphylococcus aureus was found to be the most common organism in pin tract infections. Our results were very near to Behrens and Searls $112 \%$ and Edwards ${ }^{11} 11 \%$.

There were 3 cases of pin tract infection requiring only local care and oral antibiotics. In our series, low incidence may be contributed by Increased use of Anteromedial half pins, bicortical placement of Schanz pins, predrilling using fresh sharp drills, reduce thermal necrosis of bone by using a hand drill, ample release of tensed skin, early coverage of wound, meticulous pin care. ${ }^{15}$

Ankle stiffness was seen in 3 cases (10\%). In most of the cases, it was found to be due to anterior compartment involvement in injury. This complication can be eliminated by routine use of either a dorsiflexion splint on the tibiometatarsal extension for all cases with anterior compartment muscle loss. The foot should be dorsiflexed to the neutral position before inserting the transfixing pins.

There were five cases of non-union $(16.6 \%)$ in our study.

In two cases, the fracture failed to unite probably because of excessive comminution and detaching of the segment from the surrounding tissue or bone loss initially. These two cases were managed by Ilizarov ring fixator and solid union was achieved. In remaining two cases with nonunion Intramedullary nail was put with posterolateral bone grafting. Failure of fracture union in these cases was managed well by secondary intramedullary nailing, which did not compromise the end result. ${ }^{16}$ In one case with large defect at the distal third leg., which resulted in gap nonunion Tibialisation of fibula was done which also united with mild ankle stiffness. In our series the nonunion rate was $16.6 \%$, however in Edwards et al ${ }^{11}$ it is 3\% and $20-30 \%$ in Gustilo et al series. Out of two one patient died in the hospital four months after admission. She sustained a compound fracture Grade I of the opposite limb also. A disarticulation of the left knee joint was done and stump was infected, cause of death 
was septicaemia with cardiogenic shock and pulmonary embolism.

Other patient who was discharged one month after wound debridement and fixator application, had uncontrolled Diabetes and was on Insulin and died of diabetic ketoacidosis. In our study, Karlstrom criteria was considered. Accordingly, the results were Excellent in 50\% cases, Good in $23.33 \%$ cases, Acceptable in $10.00 \%$ cases, Poor in $6.67 \%$ cases, Death and Lost to followup in $10.00 \%$ cases. Average time for Union was 6.2 months.

\section{CONCLUSION}

By knowing the technique and biomechanics, application of external fixator can act as a definite and safest method of treatment in open tibial fractures.

Restoration of skeletal stability with external fixator helps in the management of wounds. Serial debridement and soft tissue coverage of the wound could be done with the fixator in place. Free flap coverage of the wound could be done early. Daily dressings of the wound can be done while the fracture site is kept stable. The primary free flap cover has shown to reduce the time of fracture healing, need for bone grafting and the prevalence of post-traumatic osteomyelitis. The overall functional result with primary free flap cover in an ideal case is as good as in a closed fracture.

Stability of the fracture site can be increased by using triangular frames and Double bar anterior unilateral frames. The morale of the patient is boosted, because he can be mobilised with a pair of crutches and can do daily activities as a normal person except weight bearing on the limb (with ground touch gait). Any rotations, alignment of the fracture site and reduction can be done. Equinus contracture of the ankle can be prevented either by adding tibiometatarsal frames or attaching foot splint to external fixator. Limb length is well maintained in spite of severe comminution and bone loss.

Early Bone grafting can reduce the fracture healing time and complications of external fixator.

External fixator should be discontinued once the wound cover is matured and fracture callus is seen. Prolonged use of external fixator device, particularly non-weight-bearing can lead to delayed union and nonunion. Initial rigid fixation followed by early fixator removal and the use of functional casts to permit axial loading would seem to be ideal.

\section{REFERENCES}

[1] Behrens F, Comfort TH, Searls K, et al. Unilateral external fixation for severe open tibial fractures: preliminary report of a prospective study. Clin Orthop 1983;178:111.
[2] Chapman MW. The use of immediate internal fixation in open fractures. Orthop Clin North Am 1980;11(3):579-91.

[3] Lottes J0. Medullary nailing of tibia with the triflange nail. Clin Orthop Relat Res 1974;105:53-66.

[4] Chapman MW, Madison M. Open fractures. Operative Orthopaedics. Vol 1. $2^{\text {nd }}$ ed. Philadelphia: Lippincott 1993:369.

[5] Chapman MW, Madison M. External fixation: general principles and application in the lower leg. Operative orthopaedics. Vol 1. $2^{\text {nd }}$ ed. Philadelphia: Lippincott 1993:355.

[6] Tornetta P, Bergman M, Watnik N, et al. Treatment of grade III B open tibial fractures a prospective randomized comparison of external fixator to non reamed locking nailing. JBJS 1994;76(1):13-9.

[7] Gustilo RB, Anderson JT. Prevention of infection in treatment of 1025 open fractures of long bones: retrospective and prospective analysis. J Bone Joint Surg Am 1976;58(4):453-8.

[8] Etter C, Burri C, Claes L, et al. Treatment of external fixation of open fractures associated with severe soft tissue damage of the leg. Clin Orthop Relat Res 1983; 178:80-8.

[9] Karlstrom G, Olernd S. External fixation of severe open tibial fractures with the Hoffman frame. Clin Orthop Relat Res 1983;180:68-77.

[10] Karlstrom G, Olerud S. Percutaneous pin fixation of open tibial fractures. Double-frame anchorage using the Vidal-Adrey method. J B J S 1975;57(7):915-24.

[11] Edwards CC, Simmons SC, Browner BD, et al. Severe open tibial fractures: results treating 202 injuries with external fixation. Clin Orthop Relat Res 1988;230:98115.

[12] Thakur AJ, Patankar J. Open tibial fractures. Treated by uniplanar external fixation and early bone grafting. J B J S Br 1991;73(3):448-51.

[13] Linden V, Larsson K. Plate fixation versus conservative treatment of tibial shaft fractures. A randomized trial. J B J S 1979;61(6):873-8.

[14] Velazco A, Whitesides TE, Fleming LL. Open fractures of tibia treated by lottes nail. J Bone Joint Surg Am 1983;65(7):879-85.

[15] Behrens F, Searls K. External fixation of tibia. Basic concepts and prospective evaluation. J Bone Joint Surg Br 1986;68(2):246-54.

[16] Patzakis MJ, Harvey JP, Ivler D. The role of antibiotics in the management of open fractures. J Bone Joint Surg Am 1974;56(3):532-41. 